\title{
PERANCANGAN KENDALI NAVIGASI ROBOT TANK SECARA NIRKABEL BERBASIS SENSOR ACCELEROMETER BERDASARKAN GERAKAN TANGAN
}

\author{
Muhamad Yusvin Mustar \\ Fakultas Teknik, Program Studi Teknik Elektro \\ Universitas Muhammadiyah Yogyakarta \\ Email: yusvin@umy.ac.id \\ Yudhi Ardiyanto \\ Fakultas Teknik, Program Studi Teknik Elektro \\ Universitas Muhammadiyah Yogyakarta \\ Email: yudhi.ardiyanto@umy.ac.id
}

\begin{abstract}
ABSTRAK
Sebuah sistem kendali berbeda pada navigasi robot tank diperkenalkan pada penelitian ini. Umumnya sistem kendali navigasi robot tank dikendalikan meggunakan remot kontrol atau joystick dan beberapa perangkat pengontrolan robot lainya. Pengontrolan navigasi robot tank bertujuan untuk dapat mengendalikan pergerakan robot agar dapat berjalan maju, mundur, berbelok ke kiri dan ke kanan. Pada penelitian ini, pengontrolan navigasi robot dilakukan berdasarkan gerakan tangan manusia. Sebuah sarung tangan yang dilengkapi sensor accelerometer ADXL335 didesain untuk dapat mendeteksi setiap bentuk gerakan tangan. Pendeteksian gerakan tangan didasarkan pada pembacaan orientasi axis $\mathrm{X}$ dan $\mathrm{Y}$ acceleometer. Gerakan tangan ini kemudian diinput pada mikrokontroler Arduino Nano dan ditransmisikan melalui nRF24L01 2.4GHz. Hasil pendeteksian gerak kemudian diterima dan diolah pada mikrokontroler Arduino Mega yang terdapat pada robot tank. Selanjutnya, hasil pendeteksian gerakan tangan ini dipetakan dalam beberapa bagian pengontrolan, agar sesuai dengan pola pengontrolan navigasi robot tank. Hasil penelitian ini menunjukan bahwa sebuah sistem pengontrolan navigasi robot tank berdasarkan gerakan tangan dapat diimplementasikan dan diaplikasikan secara riil, sehingga dapat memberikan pengalaman baru dalam berinteraksi dengan robot.
\end{abstract}

Kata kunci: navigasi, robot tank, deteksi gerakan, accelerometer ADXL335, arduino, nRF24L01.

\begin{abstract}
A different control system on tank robot navigation was introduced in this study. Generally, the tank robot navigation control system utilizes a remote control or joystick and some robot control devices. Control of tank robot navigation aims to control the movement of the robot to be able to walk forward, backward, turn left and turn right. In this study, the control of robotic navigation is done based on the movement of the human hand. A glove equipped with an accelerometer sensor ADXL335 is designed to detect any form of hand movement. The detection of hand movements based on readings of $X$ and $Y$ axis orientation accelerometer. These hand movements subsequently inputted on the microcontroller Arduino Nano and transmitted via $n R F 24 L 012.4 G H z$. The result of motion detection is accepted and processed by Arduino Mega microcontroller on robot tank. Furthermore, the result of hand motion detection is mapped in several parts of control to fit the control pattern of tank robot navigation. The results of this study show that a control system of tank robot navigation based on hand movement can be implemented and applied in real, so it can provide a new experience in interacting with robots.
\end{abstract}

Keywords: navigation, tank robot, movement detection, accelerometer ADXL335, arduino, nRF24L01.

\section{PENDAHULUAN}

Pada bidang robotika, robot tank menjadi salah satu trend, hal ini dikarenakan bentuk roda yang menarik dan mampu bergerak atau bernavigasi pada permukaan yang tidak rata, selain itu robot tank juga cenderung lebih banyak diimplementasikan dibandingkan dengan robot beroda dan berkaki, beberapa diantaranya adalah robot bencana alam, robot penjinak bom, robot explorer dan lainya [1], Ciri khas dari robot tank adalah penggunaan aktuator motor DC (direct current) dan track wheel yang berfungsi untuk menggerakan keseluruhan badan robot, sehingga robot dapat berjalan atau berpindah posisi dari satu titik 
ke titik lainnya [2]. Beberapa penelitan yang berhubungan dengan robot tank terus dikembangkan hingga saat ini, hal tersebut dapat dilihat dari sistem kendali serta fungsi robot itu sendiri $[3,4]$.

Pada robot tank, terdapat berbagai bentuk sistem kendali, salah satu diantaranya adalah sistem kendali navigasi, kendali navigasi robot merupakan sebuah sistem pengendalian pergerakan robot dalam bernavigasi, sehingga robot dapat bergerak maju, mundur, berbelok ke kiri dan berbelok ke kanan. Umumnya sistem kendali navigasi robot tank yang ada saat ini, masih dikendalikan dengan menggunakan berbagai media atau perangkat-perangkat pengontrolan, seperti remote kontrol atau joystick, smartphone serta berbasis tampilan visual pada komputer berbasis GUI (graphical user interface), berbeda halnya dengan sistem kendali robot pada umumnya, penelitian ini mengembangkan dan mengusulkan sebuah sistem kendali navigasi robot tank berdasarkan gerakan tangan manusia yang didasari pada metode pendeteksian gerak berbasis sensor.

Metode pendeteksian gerakan berbasis sensor atau yang disebut dengan non optik merupakan salah satu metode yang dapat digunakan selain metode berbasis penglihatan (vision) yang memerlukan kamera eksternal, emitter atau penanda (marker) [5], salah satu sensor yang diaplikasikan dan digunakan sebagai metode pendeteksi gerakan adalah sensor accelerometer. Pada perkembanganya telah ada beberapa penelitian sebelumnya yang membahas penggunaan sensor accelerometer sebagai metode pendeteksian gerak khusunya dalam pengontrolan robot, diantaranya pengendalian mobil robot berdasarkan gerakan tangan [6,7], pengendalian robot berdasarkan pengenalan gerakan menggunakan sensor accelerometer pada smartphone [8] serta pengontrolan lengan robot [9,10], sedangkan pada penelitian ini mengusulkan sebuah sistem pengontrolan navigasi robot tank secara nirkabel berdasarkan gerakan alamiah tangan yang dimodelkan dalam beberapa bentuk skenario pengontrolan robot yang menyerupai pola gerakan tangan manusia.

Sistem yang di bangun pada penelitian ini didasari pada metode pendeteksian gerak berbasis sensor accelerometer ADXL335 seacara real time, sensor tersebut terpasang pada sebuah sarung tangan (glove) yang di desain agar dapat dikenakan dan digunakan pada tangan manusia, sebuah algoritma pengontrolan robot berdasarkan hasil pendeteksian gerakan tangan di rancang dan diterapkan pada robot, sehingga pengendalian navigasi robot tank dapat dilakukan hanya dengan menggerakan tangan sesuai dengan skenario yang telah ditentukan.

\section{METODOLOGI PENELITIAN}

Metode penelitian ini terbagai atas beberapa bagian utama yang bertujuan untuk merealisasikan pengendalian navigasi robot tank berbasis sensor accelerometer berdasarkan gerakan tangan manusia, beberapa bagian utama diantaranya adalah perancangan hardware, perancangan skenario pengendalian navigasi robot tank dan perancangan program.

\subsection{Perancangan Hardware}

Beberapa komponen perangkat keras (hardware) digunakan pada penelitian ini, guna merealisasikan sistem kendali navigasi robot tank berbasis sensor accelerometer berdasarkan gerakan tangan, gambar 1 memperlihatkan blok diagram perancangan hardware sistem kontrol navigasi robot tank.

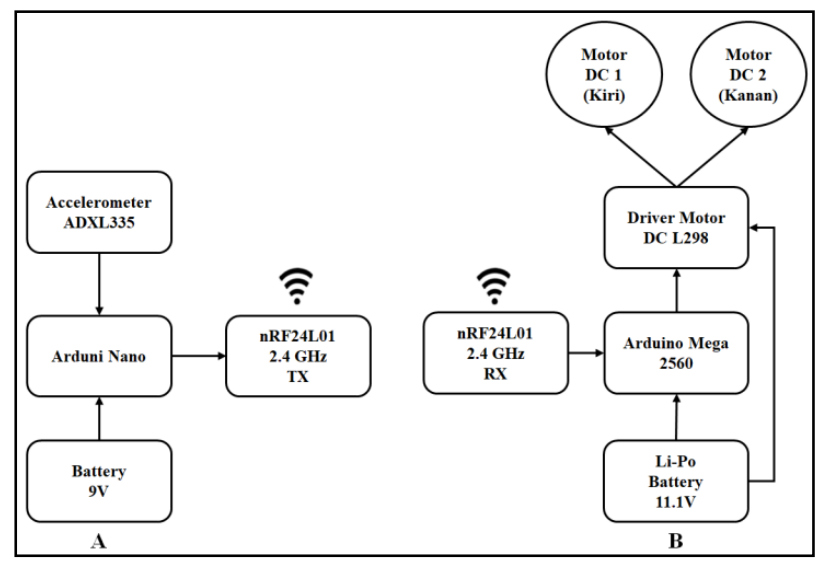

Gambar 1. Blok Diagram Perancangan Hardware Sistem Kontrol Navigasi Robot Tank 
Seperti yang terlihat pada gambar 1, blog diagram terbagi atas dua bagian, yaitu bagian A dan B. Bagian A merupakan sistem pendeteksian gerakan tangan dan akan dipasang pada sebuah sarung tangan untuk dapat dikenakan oleh tangan manusia, sedangkan bagian B merupakan sistem robot tank yang akan bernavigasi berdasarkan gerakan tangan. Beberapa komponen utama yang terdapat pada blok diagram perancangan hardware diterangkan sebagai berikut.

\subsubsection{Sensor Accelerometer ADXL335}

Penggunaan jenis sensor accelerometer ADXL335, tidak lepas dari kinerja sensor yang unggul, ukuran yang kecil, dan berdaya rendah namun dengan biaya yang murah [11]. Sensor ADXL335 terdiri dari 3 axis (sumbu) X, Y dan Z. Sensor ini mampu mengukur percepatan dengan range sebesar $\pm 3 \mathrm{~g}$ (gravitasi), sensor tersebut mempunyai keluaran (output) analog berupa tegangan yang dapat diformulasikan dalam persamaan (1) berikut ini [11].

$$
V_{\text {out }}=(\mathrm{a} \times \mu) \mathrm{V}_{\text {og }}
$$

$$
\begin{aligned}
& \text { Dengan : } \\
& \begin{aligned}
\mathrm{V}_{\text {out }} & =\text { Keluaran sensor }(\mathrm{V}) \\
\mathrm{a} & =\text { Percepatan aktual }(\mathrm{g}) \\
\mu & =\text { Sensitivitas sensor }(\mathrm{V} / \mathrm{g}) \\
\mathrm{V}_{0 \mathrm{~g}} & =\text { Tegangan } 0 \mathrm{G}(\mathrm{V})
\end{aligned}
\end{aligned}
$$

Persamaan (1) merupakan persamaan yang digunakan untuk mengetahui nilai keluaran sensor accelerometer ADXL335 yang masih berupa nilai tegangan atau analog, sensor ini menggunakan struktur tunggal untuk melakukan penginderaan pada setiap axis X, Y dan Z [12], gambar 2 memperlihatkan blok diagram fungsional sensor accelerometer ADXL335, sedangkan gambar 3 memperlihatkan respon output dan orientasi gravitasi sensor accelerometer ADXL335

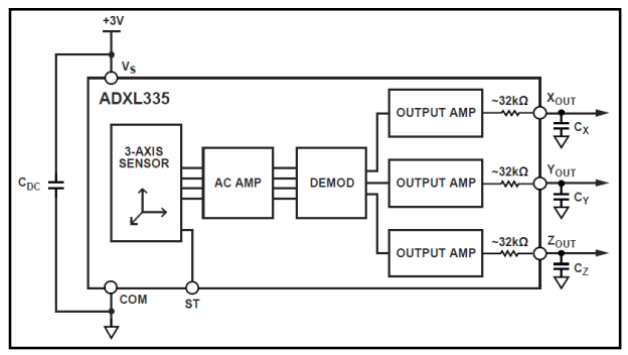

Gambar 2. Blok Diagram Fungsional Sensor Accelerometer ADXL335 [13]

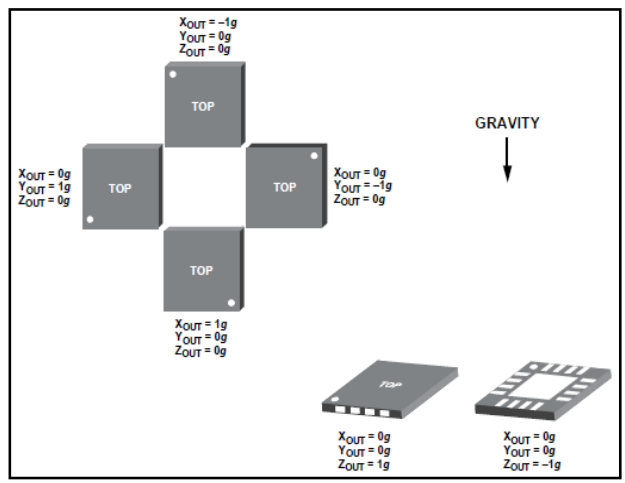

Gambar 3. Respon Output Dan Orientasi Gravitasi Sensor Accelerometer ADXL335 [13]

Sensor accelerometer ADXL335 beroperasi pada tegangan 1,8V sampai dengan 3,6 V dengan tegangan tipikalnya sebesar 3,3 V. Sensitivitas dari sensor ADXL335 antara $270 \mathrm{mV} / \mathrm{g}$ sampai dengan $330 \mathrm{mV} / \mathrm{g}$ dengan tipikal $300 \mathrm{mV} / \mathrm{g}$ pada kondisi tegangan masukan (input) $3 \mathrm{~V}$, pengujian tegangan (volt) $0 \mathrm{~g}$ pada axis $\mathrm{X}$ dan $\mathrm{Y}$ dapat dilakukan pada kondisi axis $\mathrm{Z}$ mendapatkan respon output dan orientasi gravitasi sebesar $1 \mathrm{~g}$, karena pada saat output axis $\mathrm{Z}=1 \mathrm{~g}$, axis $\mathrm{X}$ dan $\mathrm{Y}$ mendapatkan respon output dan orientasi gravitasi $=0 \mathrm{~g}$, sedangkan untuk pengujian tegangan $0 \mathrm{~g}$ pada axis $\mathrm{Z}$ dapat ditentukan dengan 
metode nilai tengah dari rata-rata kondisi tegangan output axis $\mathrm{Z}=1 \mathrm{~g}$ dan tegangan output axis $\mathrm{Z}=-1 \mathrm{~g}$ yang dapat diformulasikan dalam persamaan (2) berikut ini [12].

$$
\begin{aligned}
& V_{\text {Og }} \text { axis } Z=\frac{V_{x[1 g]+}+V_{z x[-1 g)}}{2} \\
& \text { Dengan : } \\
& V_{0 g} \text { axis } Z=\text { Tegangan } 0 \mathrm{~g}(\mathrm{~V}) \text { pada axis } \mathrm{Z} \\
& V_{z(1 g)}=\text { Tegangan output axis } \mathrm{Z}=1 \mathrm{~g} \\
& V_{z(-1 g)}=\text { Tegangan } \text { output axis } \mathrm{Z}=-1 \mathrm{~g}
\end{aligned}
$$

Persamaan (2) digunakan untuk mengetahui nilai tegangan keluaran axis $\mathrm{Z}$ pada saat $0 \mathrm{~g}$, metode ini mengacu pada gambar 3 dengan mengambil nilai tengah pada saat axis $\mathrm{Z}$ mendapatkan respon output dan orientasi gravitasi sebesar $1 \mathrm{~g}$ dan $-1 \mathrm{~g}$, sebaliknya axis $\mathrm{X}$ dan $\mathrm{Y}$ nilai $0 \mathrm{~g}$ dapat di ketahui pada saat axis $\mathrm{Z}=1 \mathrm{~g}$ dan axis $\mathrm{Z}=-1 \mathrm{~g}$. Pada penelitian ini pendektesian gerakan tangan hanya mengacu pada respon output dan orientasi gravitasi axis $\mathrm{X}$ dan $\mathrm{Y}$.

\subsubsection{Arduino}

Arduino adalah nama keluarga pada papan (board) mikrokontroler yang bersifat open source yang bertujuan untuk memudahkan eksperimen atau mewujudkan berbagai peralatan berbasis mikrokontroler [14]. Terdapat dua buah mikrokontroler Arduino yang digunakan pada penelitian ini, yaitu arduino Nano dan arduino Mega. Seperti yang terlihat pada blok diagram perancangan hardware, arduino nano dengan tipe mikrokontroler ATmega328 digunakan untuk membaca keluaran (output) sensor accelerometer yang masih berupa analog, untuk di konversi menjadi data digital melalui ADC (analog digital converter) yang dapat diformulasikan dalam persamaan (3) berikut ini.

$$
\begin{aligned}
& A D C=\frac{\text { Vin }}{\text { Vref }} \times \text { Resolusi } A D C \\
& \text { Dengan }: \\
& \text { ADC }=\text { Analog digital converter } \\
& \text { Vin }=\text { Tegangan Input } \\
& \text { Vref }=\text { Tegangan Reverensi } \\
& \text { Resolusi ADC }=\text { Nilai resolusi ADC }
\end{aligned}
$$

Persamaan (3) dapat digunakan untuk mengetahui berapa nilai hasil konversi tegangan analog (volt) output axis $\mathrm{X}$ dan Y kebentuk nilai digital atau (decimal), proses ini dilakukan pada Pin analog arduino nano sebagai tegangan input (Vin) sensor yang akan di konversi menjadi digital, arduino nano memiliki nilai resolusi ADC 10 bit $\left(2^{10}\right)$, dengan nilai skala penuh 1024, namun perlu diketahui karena dimulai dari angka decimal 0 nilai konversi resolusi ADC adalah 0-1023, sehingga nilai skala penuhnya dalam decimal adalah 1023, dengan tegangan referensi (Vref) arduino nano sebesar 5 Volt.

Data ADC yang diperoleh kemudian diproses menjadi data pendeteksian gerakan tangan, untuk di transmisikan secara nirkabel, sedangkan arduino Mega dengan tipe mikrokontroler Atmega 2560 digunakan sebagai media pemrosesan data hasil pendeteksian gerak, untuk selanjutnya diolah sebagai pengendalian navigasi robot tank berdasarkan gerakan tangan.

\subsection{3 nRF24LO1}

NRF24L01 merupakan modul komunikasi serial secara nirkabel yang didesain untuk aplikasi ultra low power wireless dengan pita frekuensi ISM 2,4 GHz, modul ini dapat dikonfigurasi dan dioperasikan melalui antarmuka perangkat serial, selain itu nRF24L01 memiliki 2 mode yaitu TX dan RX, TX merupakan mode saat NRF24L01 berfungsi sebagai pengirim paket data, sedangkan RX merupakan mode saat NRF24L01 berfungsi sebagai penerima paket data [15].

Dua buah modul nRF24L01 digunakan pada penelitian ini, pada sisi TX nRF24L01 berfungsi mengirimkan data-data hasil pendeteksian gerakan tangan yang terdeteksi oleh sensor accelerometer, sedangkan pada sisi RX berfungsi menerima data-data hasil pendeteksian gerakan tangan untuk selanjutnya diolah sebagai pengendalian navigasi robot tank.

\subsubsection{Driver Motor}

Driver motor DC yang digunakan pada penelitian ini adalah L298, driver ini digunakan untuk mengendalikan dua buah motor DC yang berfungsi menggerakkan track wheel robot tank, driver ini 
mendapatkan input pengendalian direction dari mikrokontroler arduino mega, sehingga robot dapat bergerak maju, mundur, berbelok ke kiri dan berbelok ke kanan.

\subsection{Perancangan Skeneario Pengendalian Navigasi Robot}

Pada tahapan ini, skenario pengendalian navigasi robot tank berdasarkan gerakan tangan ditentukan, pendekatan sistem kendali yang digunakan pada penelitian ini adalah menguraikan setiap masalah ke dalam rangkaian unit fungsional seperti yang diperlihatkan pada gambar 4 berikut ini.

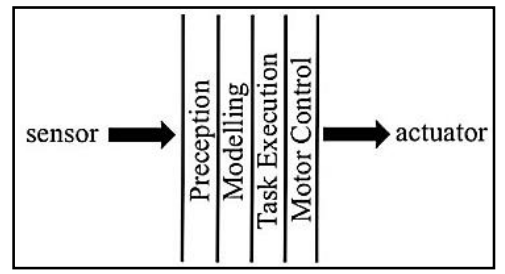

\section{Gambar 4. Teknik Penguraian Sistem Kendali Robot Ke Dalam Unit-Unit Fungsional [16]}

Seperti yang terlihat pada gambar 4, dalam merancang sebuah sistem kendali, salah satu metode yang dapat digunakan adalah behavior based robotic, tahapan pertama yang dilakukan adalah membaca nilai sensor sebagai inputan ke dalam sistem, kemudian mempresepsikan nilai tersebut sebagai suatu satuan (perception) dan memodelkannya ke dalam bentuk suatu persamaan (modelling) sehingga dapat merencanakan (planning) pergerakan robot, tahap selanjutnya mengeksekusi perencanaan yang telah dilakukan (task execution) untuk mengendalikan motor sebagai penggerak atau actuator robot (motor control) $[16,17]$.

Pembacaan respon output dan orientasi gravitasi sensor accelerometer dalam melakukan pendeteksian gerakan tangan dipresepsikan untuk dapat dimodelkan dalam beberapa skenario pengendalian navigasi robot tank. Untuk dapat melakukan pengendalian navigasi robot tank tahapan awal yang dilakukan adalah menentukan posisi sensor accelerometer ADXL335 pada tangan, seperti yang di perlihatkan pada gambar 5 .

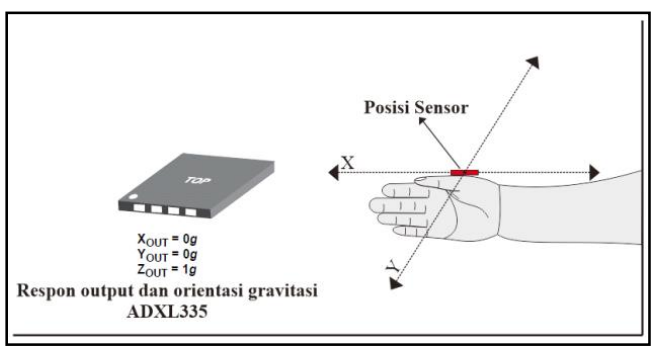

\section{Gambar 5. Posisi Sensor Accelerometer Pada Tangan}

Pada posisi ini, sensor accelerometer akan mendapatkan respon output dan orientasi gravitasi sebesar $0 \mathrm{~g}$ pada axis $\mathrm{X}$ dan axis $\mathrm{Y}$, hal ini mengacu pada datasheet sensor, selain itu posisi ini dijadikan sebagai kondisi atau skenario awal untuk memulai interaksi pengendalian navigasi robot tank, untuk memposisikan sensor seperti pada gambar 5, sebuah sarung tangan didesain yang dilengkapi dengan sensor accelerometer, arduino nano dan sebuah baterai.

Sistem pengendalian navigasi robot dibagi dalam beberapa bentuk skenario pengendalian yang di dimodelkan berdasarkan gerakan tangan, model-model pengendalian tersebut di bagi dalam lima skenario pengendalian dengan fungsi yang berbeda-beda, setiap bentuk pergerakan tangan mewakili sebuah interaksi pengendalian navigasi robot. Gambar 6 memperlihatkan skenario pengendalian navigasi robot tank berdasarkan gerakan tangan. 


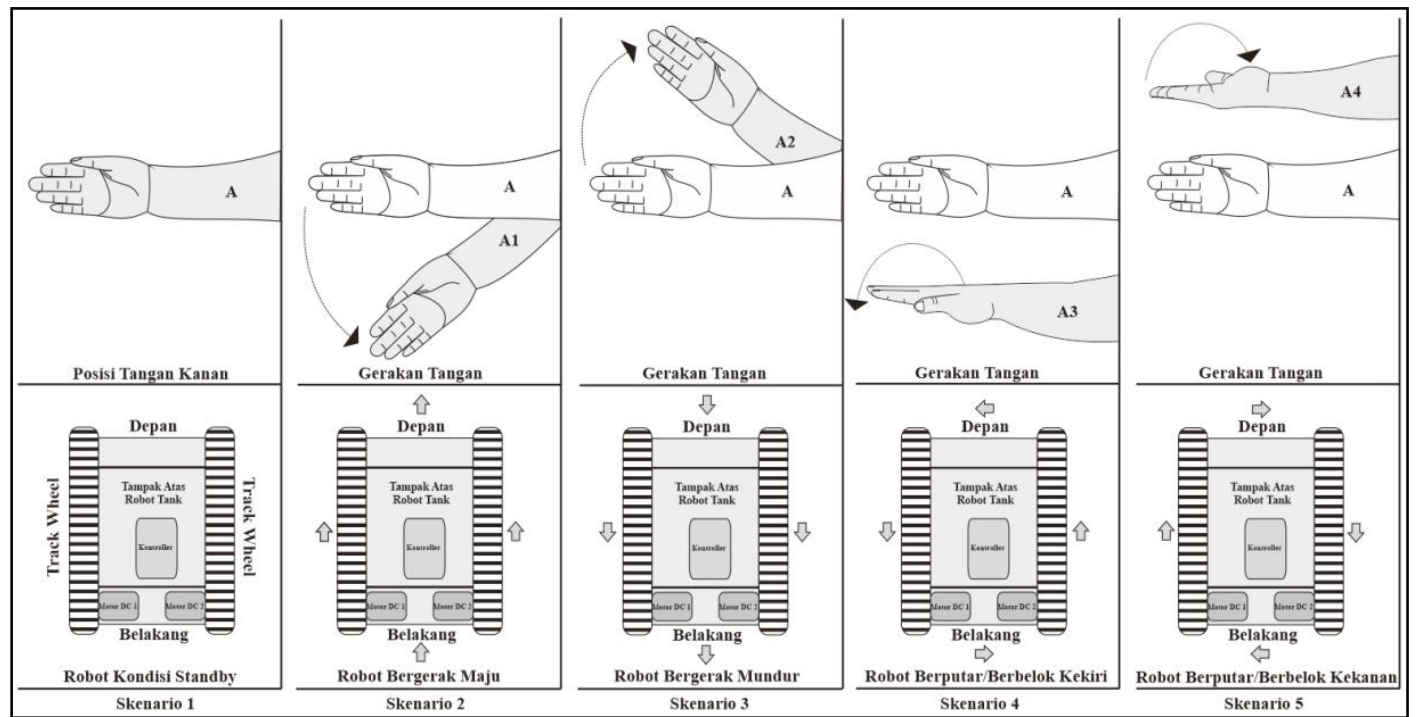

Gambar 6. Skenario Pengendalian Navigasi Robot Tank Berdasarkan Gerakan Tangan

Pada gambar 6, skenario 1 merupakan kondisi awal saat ingin melakukan pengendalian navigasi robot tank ketika robot dalam keadaan aktif $(O N)$, pada skenario ini sensor accelerometer membaca respon output dan orientasi gravitasi sebesar 0g pada axis X dan axis Y, sistem kontrol pada kondisi ini memberikan pengendalian robot untuk standby, posisi ini juga digunakan untuk memerintahkan robot berhenti atau stop.

Skenario 2, posisi tangan digerakkan dari posisi A ke A1, pada kondisi tersebut sensor akan mendeteksi gerakan tangan berdasarkan axis $\mathrm{X}$ dengan respon output dan orientasi gravitasi 0g hingga -1g (kurang dari $0 \mathrm{~g}$ ), sistem kontrol pada kondisi ini memberikan pengendalian navigasi robot bergerak maju ke depan dan akan berhenti jika tangan digerakkan kembali ke posisi A, sedangkan skenario 3 merupakan kebalikan dari skenario 2, yaitu sistem kontrol yang memberikan pengendalian navigasi robot bergerak mundur ke belakang dan berhenti pada saat tangan kembali keposisi A, dengan kondisi respon output dan orientasi gravitasi sensor adalah $0 \mathrm{~g}$ hingga $1 \mathrm{~g}$ (lebih dari $0 \mathrm{~g}$ ) pada axis X.

Untuk skenario 4 posisi tangan digerakkan dari posisi A ke A3, pada kondisi ini sensor accelerometer akan mendeteksi gerakan tangan berdasarkan axis $\mathrm{Y}$ dengan respon output dan orientasi gravitasi $0 \mathrm{~g}$ hingga $-1 \mathrm{~g}$ (kurang dari $0 \mathrm{~g}$ ), sistem kontrol pada kondisi ini memberikan pengendalian navigasi robot bergerak berbelok ke kiri secara berputar, apabila posisi tangan terus berada di posisi A3 robot akan beruputar ke kiri secara terus menerus, hingga akhirnya robot berhenti jika tangan kembali ke posisi A, sedangkan skenario 5 merupakan kebalikan pengendalian dari skenario 4, kondisi ini respon output dan orientasi gravitasi sensor adalah $0 \mathrm{~g}$ hingga $1 \mathrm{~g}$ (lebih dari $0 \mathrm{~g}$ ) pada axis $\mathrm{Y}$, dengan bentuk pengendalian navigasi robot bergerak berbelok ke kanan secara berputar dan berhenti pada saat tangan kembali ke posisi A.

Pengendalian navigasi robot tank sepenuhnya dipengaruhi oleh user sehingga sistem kontrol robot mengacu pada sistem kontrol loop terbuka (open loop), kontrol loop terbuka atau umpan maju (feedforward control) dapat dinyatakan sebagai sistem kontrol yang keluarannya tidak diperhitungkan ulang oleh controller [18].

\subsection{Perancangan Program}

Perancangan program pada penelitian ini terbagi dalam dua bagian, yaitu perancangan program pada mikrokontroler arduino nano yang berfungsi sebagi sistem pendeteksian gerakan tangan berbasis sensor accelerometer dan perancangan program pada mikrokontroler arduino mega yang difungsikan sebagai sistem robot tank. Program robot dibuat menggunakan arduino IDE (Integrated Development Environment) versi 1.6.12 dan sebuah library RF24.h agar modul nirkabel NRF24L01 dapat di gunakan sesuai dengan fungsinya, berikut perancangan program disajikan dalam bentuk flowchart seperti yang terlihat pada gambar 7 berikut ini, gambar 7 bagian A memperlihatkan flowchart perancangan program pendeteksian gerakan tangan sedangkan gambar 7 bagian B memperlihatkan flowchart perancangan program pada robot. 


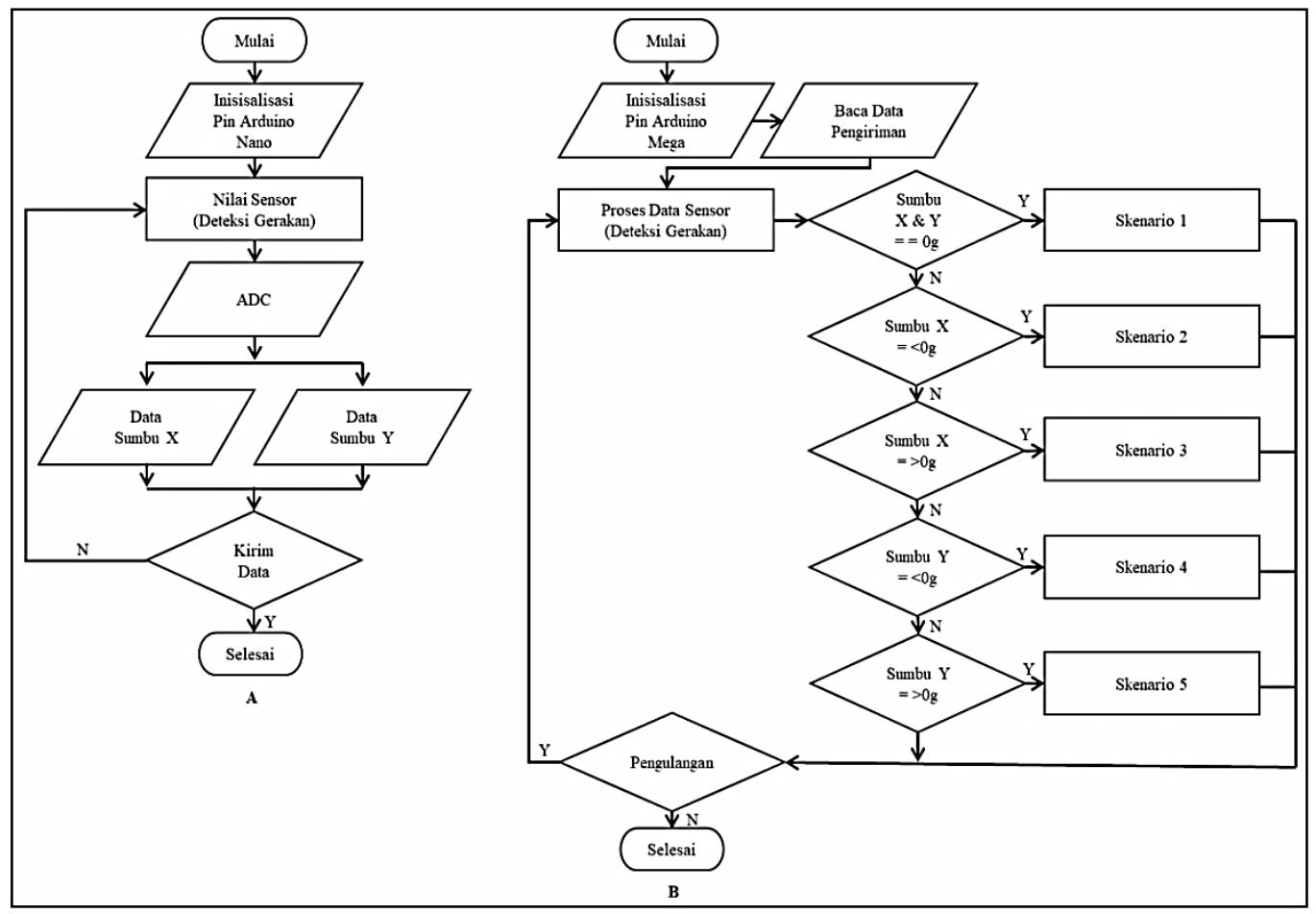

Gambar 7. Flowchart Perancangan Program

\section{HASIL DAN PEMBAHASAN}

Pada hasil pengujian sensor accelerometer ADXL335 didapatkan nilai decimal ADC respon output dan orientasi gravitasi, seperti yang diperlihatkan pada tabel 1 berikut ini.

Tabel 1. Nilai ADC respon output dan orientasi gravitasi pada sensor accelerometer ADXL335

\begin{tabular}{ccc}
\hline Gravitasi $(\mathbf{g})$ & Nilai Decimal ADC Axis $\boldsymbol{X}$ & Nilai Decimal ADC Axis $\boldsymbol{Y}$ \\
\hline$-\lg (<0 g)$ & $267($ Min $)$ & $268($ Min $)$ \\
$0 g$ & 335 & 338 \\
$\lg (>0 g)$ & $405($ Max $)$ & $410($ Max $)$ \\
\hline
\end{tabular}

Berdasarkan tabel 1 dapat dilihat bahwa nilai orientasi gravitasi pada axis $\mathrm{X}$ memiliki nilai decimal ADC minimum 267 (-1g) sampai dengan nilai decimal maksimum 405 (1g), sedangkan pada axis Y nilai orientasi gravitasi pada axis Y memiliki nilai decimal ADC minimum 268 (-1g) sampai dengan nilai desimal maksimum $410(1 \mathrm{~g})$.

Nilai decimal ADC respon output dan orientasi gravitasi inilah yang diproses dan dijadikan acuan dalam melakukan pendeteksian setiap gerakan pada masing-masing skenario pengendalian navigasi robot tank, setiap pengendalian navigasi memiliki nilai ADC respon output dan orientasi gravitasi yang berbeda-beda seperti diperlihatkan pada hasil pengujian masing-masing skenario pengenalian navigasi robot tank.

\subsection{Hasil Pengujian Skenario 1}

Hasil pengujian skenario 1 diperlihatkan pada gambar 8. 


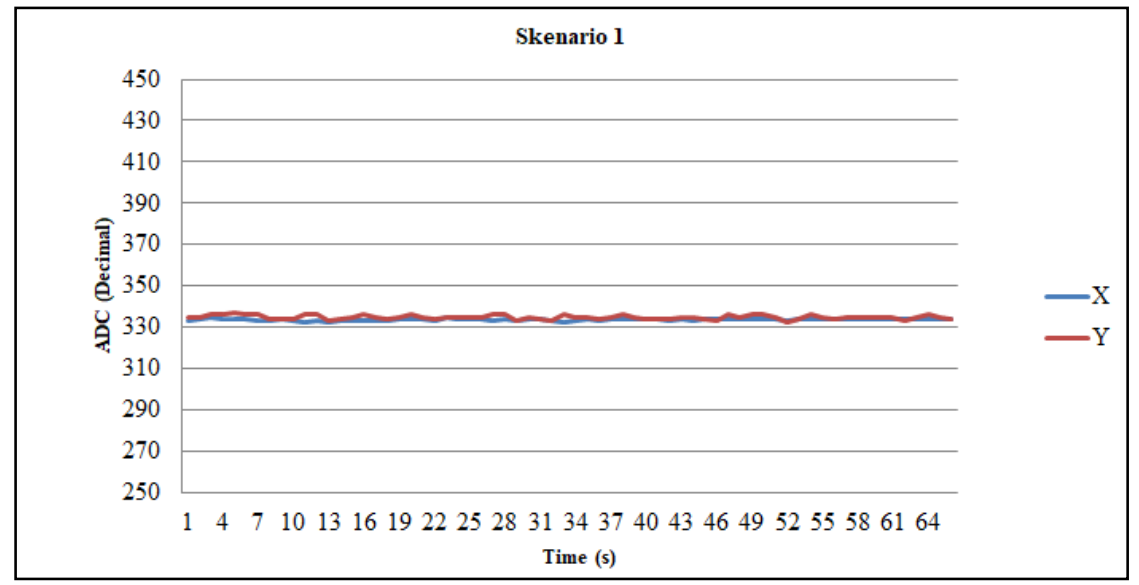

Gambar 8. Grafik Hasil Pengujian Skenario 1

Seperti yang terlihat pada gambar 8, grafik axis X dan Y hampir memilki kesamaan respon output dan orientasi gravitasinya saat tangan berada pada posisi skenario 1, hasil pengujian ini menunjukan robot dapat berhasil standby atau posisi berhenti (stop), diam dan tidak bergerak, dengan kondisi track wheel robot seperti yang diperlihatkan pada tabel 2, kondisi ini juga di gunakan sebagai brake atau pengereman pada saat mengendalikan navigasi robot tank, sehingga memudahkan pengguna dalam mengoperasikannya.

Tabel 2. Kondisi track wheel robot tank pada saat pengujian skenario 1

\begin{tabular}{cc}
\hline Motor DC & Arah Gerakan Track Wheel \\
\hline Motor DC 1 & Stop/Brake \\
Motor DC 2 & Stop/Brake \\
\hline
\end{tabular}

\subsection{Hasil Pengujian Skenario 2}

Untuk pengujian skenario 2 diperlihatkan pada gambar 9 berikut ini

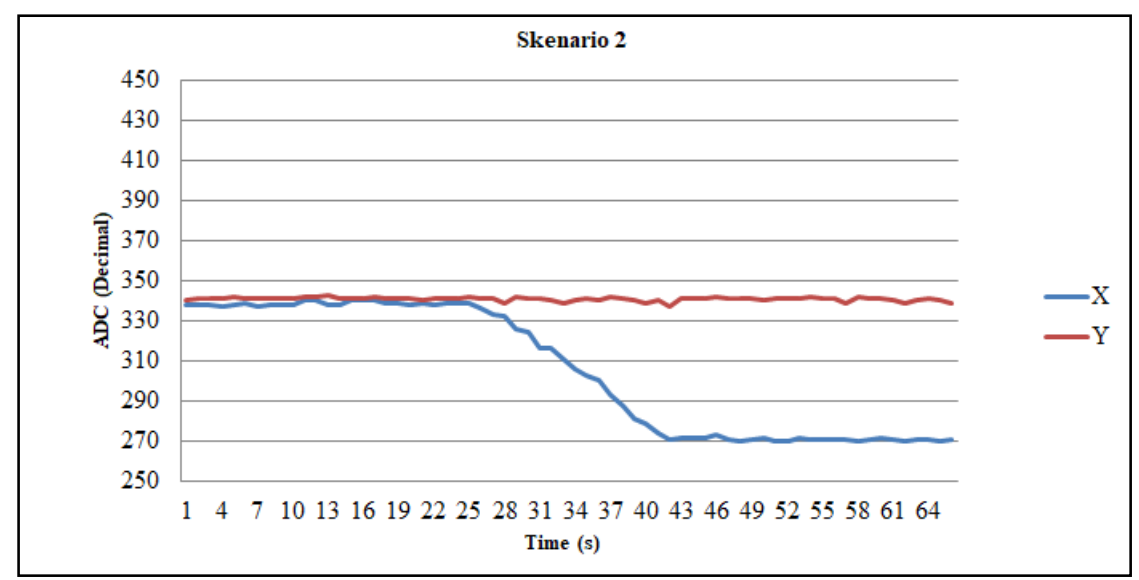

Gambar 9. Grafik Hasil Pengujian Skenario 2

Pada pengujian skenario 2, dapat dilihat hasil grafik axis $\mathrm{X}$ mengalami perubahan respon output dan orientasi gravitasinya, axis $\mathrm{X}$ dapat mendeteksi adanya perubahan gerakan tangan seperti yang di tunjukan pada perancangan skenario 2, dengan orientasi gravitasi hampir mendekati - $1 \mathrm{~g}$ (kurang dari $0 \mathrm{~g}$ ), hasil pengujian ini menunjukkan robot yang semula berada pada posisi standby dapat bernavigasi bergerak maju ke depan.

Pada saat robot bergerak maju ke depan motor DC 1 dan motor DC 2 menggerakkan track wheel robot tank searah jarum jam (clockwise), tabel 3 memperlihatkan kondisi pergerakan track wheel pada saat robot tank bergerak ke depan. 
Tabel 3. Kondisi pergerakan track wheel pada saat robot tank bergerak ke depan

\begin{tabular}{cc}
\hline Motor DC & Arah Gerakan Track Wheel \\
\hline Motor DC 1 & Clockwise $(C W)$ \\
Motor DC 2 & Clockwise $(C W)$ \\
\hline
\end{tabular}

\subsection{Hasil Pengujian Skenario 3}

Hasil pengujian skenario 3 diperlihatkan pada gambar 10 berikut ini.

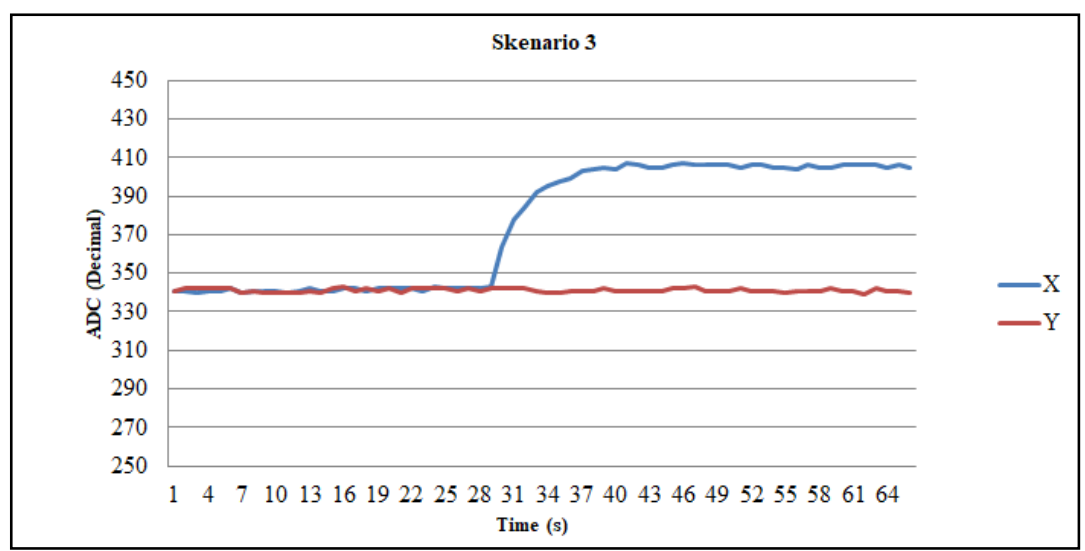

Gambar 10. Grafik Hasil Pengujian Skenario 3

Seperti yang terlihat pada gambar 10, pengujian skenario 3 merupakan kebalikan pengendalian navigasi pada skenario 2, hal tersebut dapat dilihat pada grafik hasil pengujian yang memperlihatkan axis $\mathrm{X}$ mengalami perubahan respon output dan orientasi gravitasi pada saat mendeteksi gerakan tangan seperti yang ditunjukan pada perancangan skenario 3, dengan orientasi gravitasi axis $\mathrm{X}$ hampir mendekati $1 \mathrm{~g}$ (lebih dari $0 \mathrm{~g}$ ), hasil pengujian ini menunjukkan robot yang semula berada pada posisi standby dapat berhasil bernavigasi bergerak mundur ke belakang.

Pada saat robot bergerak mundur ke belakang motor DC 1 dan motor DC 2 menggerakkan track wheel robot tank berlawanan arah jarum jam (counterclockwise), tabel 4 memperlihatkan kondisi pergerakan track wheel pada saat robot tank bergerak ke depan.

Tabel 4. Kondisi pergerakan track wheel pada saat robot tank bergerak mundur ke belakang

\begin{tabular}{cc}
\hline Motor DC & Arah Gerakan Track Wheel \\
\hline Motor DC 1 & Counterclockwise $(C C W)$ \\
Motor DC 2 & Counterclockwise $(C C W)$ \\
\hline
\end{tabular}

\subsection{Hasil Pengujian Skenario 4}

Pengujian skenario 4 diperlihatkan pada gambar 11 berikut ini.

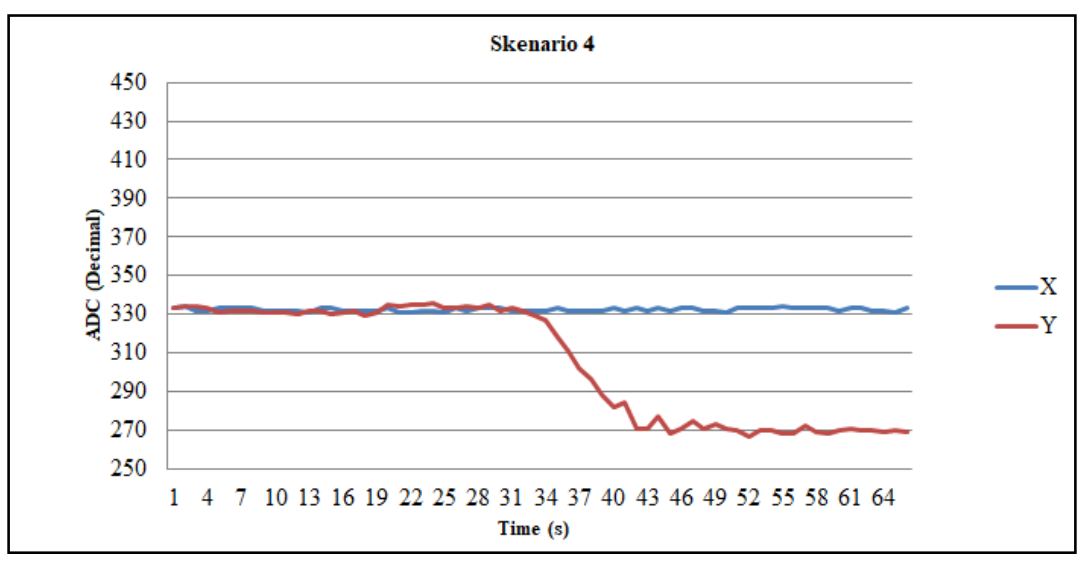

Gambar 11. Grafik Hasil Pengujian Skenario 4 
Dapat dilihat pada gambar 11, hasil pengujian skenario 4 memperlihatkan axis Y mengalami perubahan respon output dan orientasi gravitasi sampai nilai minimal -1g (kurang dari 0g), pada saat mendeteksi gerakan tangan seperti yang ditunjukan pada perancangan skenario 4 , hasil pengujian ini menunjukkan robot yang semula berada pada posisi standby dapat berhasil bernavigasi bergerak berbelok ke kiri secara berputar.

Saat robot bergerak berbelok ke kiri motor DC 1 menggerakkan track wheel berlawanan arah jarum jam (counterclockwise) sedangkan motor DC 2 menggerakkan track wheel searah jarum jam (clockwise), tabel 5 memperlihatkan kondisi pergerakan track wheel pada saat robot tank bergerak berbelok ke kiri secara berputar.

Tabel 5. Kondisi pergerakan track wheel pada saat robot tank bergerak berbelok ke kiri secara berputar

\begin{tabular}{cc}
\hline Motor DC & Arah Gerakan Track Wheel \\
\hline Motor DC 1 & Counterclockwise $(C C W)$ \\
Motor DC 2 & Clockwise $(C W)$ \\
\hline
\end{tabular}

\subsection{Hasil Pengujian Skenario 5}

Gambar 12 menunjukkan grafik hasil pengujian skenario 5

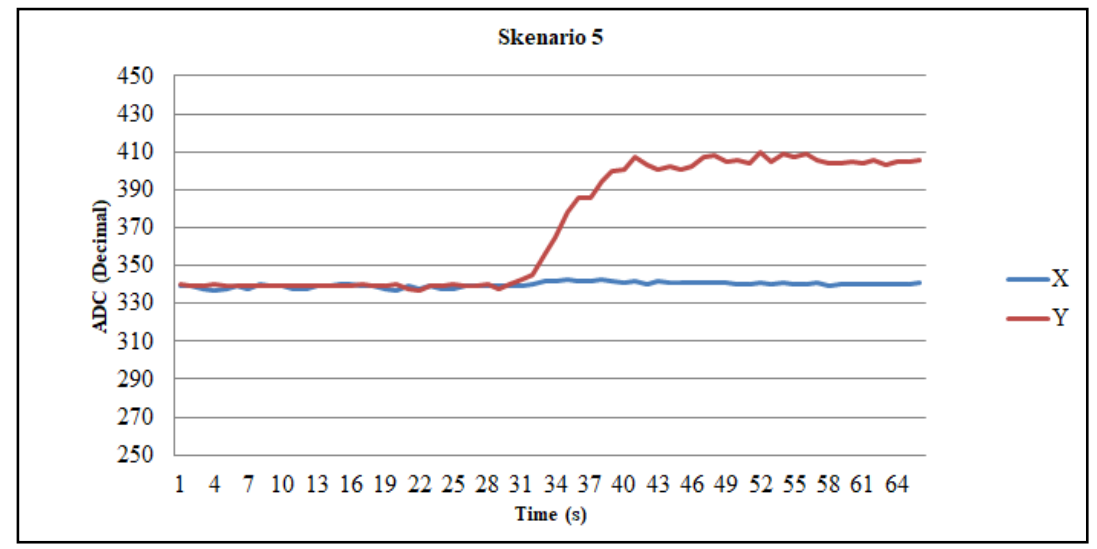

Gambar 12. Grafik Hasil Pengujian Skenario 5

Seperti yang terlihat pada gambar 12, skenario 5 merupakan kebalikan pengendalian navigasi robot tank pada skenario 4, grafik hasil pengujian skenario 5 memperlihatkan axis Y mengalami perubahan respon output dan orientasi gravitasi yang menyentuh nilai maksimal $1 \mathrm{~g}$ (lebih dari $0 \mathrm{~g}$ ), pada saat mendeteksi gerakan tangan seperti yang diperlihatkan pada perancangan skenario 5, hasil pengujian ini menunjukkan robot yang semula berada pada posisi standby dapat berhasil bernavigasi bergerak berbelok ke kanan secara berputar.

Pada saat robot bergerak berbelok ke kanan motor DC 1 menggerakkan track wheel searah jarum jam (clockwise) sedangkan motor DC 2 menggerakkan track wheel berlawanan arah jarum jam (counterclockwise), tabel 6 memperlihatkan kondisi pergerakan track wheel pada saat robot tank bergerak berbelok ke kanan secara berputar.

Tabel 6. Kondisi pergerakan track wheel pada saat robot tank bergerak berbelok ke kanan secara berputar

\begin{tabular}{cc}
\hline Motor DC & Arah Gerakan Track Wheel \\
\hline Motor DC 1 & Clockwise $(C W)$ \\
Motor DC 2 & Counterclockwise $(C C W)$ \\
\hline
\end{tabular}

\subsection{Hasil Pengujian Jarak Pengendalian Navigasi Robot Tank Secara Nirkabel Berdasarkan Gerakan Tangan}

Pengujian ini dilakukan untuk mengetahui seberapa optimalkah jarak pengendalian navigasi robot tank secara nirkabel berdasarkan modul nRF24L01 2,4GHz, pada sisi pemancar (TX) dan penerima (RX) yang berada pada robot tank, pada penelitian ini pengujian jarak pengendalian navigasi robot tank di lakukan dengan dua kondisi pengujian, kondisi pertama pengujian dilakukan di dalam ruangan dengan mengendalikan navigasi robot tank berdasarkan 5 skenario pengendalian yang telah ditentukan, 
sedangkan kondisi kedua dilakukan pengujian jarak pengendalian navigasi robot tank pada saat di luar ruangan. Tabel 7 memperlihatkan hasil pengujian jarak antara pemancar (TX) dan penerima (RX) di dalam ruangan, sedangkan tabel 8 memperlihatkan hasil pengujian jarak antara pemancar (TX) dan penerima $(\mathrm{RX})$ di luar ruangan.

Tabel 7. Hasil pengujian jarak antara pemancar (TX) dan penerima (RX) di dalam ruangan

\begin{tabular}{cc}
\hline Jarak (Meter) & Koneksi Pengendalian \\
\hline 1 & Baik \\
2 & Baik \\
3 & Baik \\
4 & Baik \\
4,3 & Terputus-putus \\
5 & Terputus-putus \\
6 & Lost \\
\hline
\end{tabular}

Tabel 8. Hasil pengujian jarak antara pemancar (TX) dan penerima (RX) di luar ruangan

\begin{tabular}{cc}
\hline Jarak (Meter) & Koneksi Pengendalian \\
\hline 1 & Baik \\
2 & Baik \\
3 & Baik \\
4 & Baik \\
5 & Baik \\
6 & Baik \\
7 & Terputus-putus \\
8 & Terputus-putus \\
9 & Terputus-putus \\
10 & Terputus-putus \\
11 & Terputus-putus \\
12 & Lost \\
\hline
\end{tabular}

Seperti terlihat pada tabel 7 dan 8, kondisi jarak terbaik dan lancar melakukan pengendalian navigasi robot tank di dalam ruangan adalah 1-4 meter, sedangkan di luar ruangan kondisi jarak terbaik dan lancar adalah 1-6 meter. Gambar 13 memperlihatkan pengujian langsung navigasi robot tank secara nirkabel berdasarkan gerakan tangan di dalam ruangan.

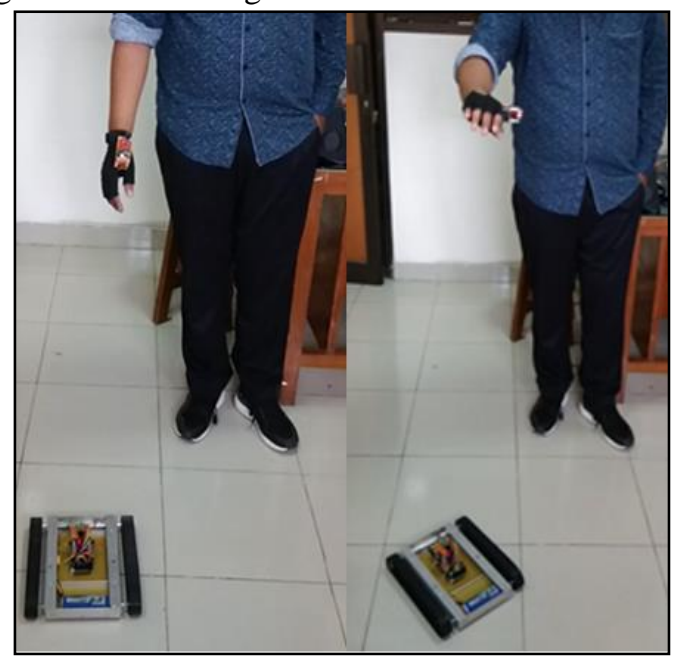

Gambar 13. Pengujian Navigasi Robot Tank Secara Nirkabel Berdasarkan Gerakan Tangan

\section{KESIMPULAN DAN SARAN}

\subsection{Kesimpulan}

Pada penelitian ini, sistem pengendalian navigasi robot tank secara nirkabel berdasarkan gerakan tangan dapat di diimplementasikan dan diaplikasikan secara riil, sensor accelerometer khususnya tipe ADXL335 dapat digunakan sebagai salah satu metode pendeteksian gerakan tangan secara real time berbasis sensor. Dari hasil beberapa percobaan dan analisa yang telah dilakukan, respon output dan 
orientasi gravitasi axis X dan Y sensor dapat melakukan penginderaan pada setiap bentuk gerakan tangan secara responsif, sehingga dapat dimodelkan menjadi sebuah sistem kontrol navigasi robot, dalam bentuk pengendalian pergerakan maju, mundur, berbelok ke kiri dan berbelok ke kanan pada robot tank secara real time. Pengendalian navigasi robot tank sepenuhnya dilakukan oleh user dengan beberapa skenario yang telah ditawarkan, sehingga hanya dengan menggerakkan tangan, user dapat berinteraksi dengan robot, dalam bentuk pengendalian navigasi robot tank secara intuitif.

\subsection{Saran}

Untuk pengembangan selanjutnya, metode perekaman gerakan tangan berdasarkan respon output dan orientasi gravitasi pada axis X, Y dan penambahan axis $\mathrm{Z}$ dapat dilakukan, sehingga tidak hanya fokus pada axis $\mathrm{X}$ dan $\mathrm{Y}$ sehingga interaksi pengendalian navigasi robot tank tidak tergantung hanya pada gerakan tangan secara real time, melainkan melalui pola gerakan tertentu sehingga dapat menambah dan memiliki berbagai bentuk pola skenario pengendalian robot selain yang telah di bahas pada penelitian ini. Selain itu dimungkinkan untuk mengganti modul nRF24L01 dengan tipe terbaru, yaitu nRF24L01+ atau nRF24L01p with PA dan LNA yang memiliki tambahan antena external, sehingga dalam melakukan pengendalian navigasi robot, jarak pengendalian bisa lebih jauh.

\section{DAFTAR PUSTAKA}

[1] Widodo, B, (2010). Robot Tank dan Navigasi Cerdas. Elex Media Komputindo.

[2] Ghifari, A, A. Rusdinar, A and Nugrah, R. 2016. "Rancang Bangun dan Implementasi Sistem Tracking Pada Robot Tank Menggunakan Android," e-Proceeding of Engineering., vol. 3, No.3.

[3] Suryadi, N. Marindani, E, D and Pontia W, F, T. 2014. "Rancang Bangun Robot Tank Yang Dilengkapi Kamera Terintegrasi Dengan Smartphone Android Via Wifi," Jurnal Teknik Elektro Universitas Tanjungpura, vol. 2, no. 1.

[4] Mustar, Muhamad Yusvin. 2011. "Implementasi Robot Tank Menggunakan Kamera CCTV Wireless Berbasis Mikrokontroler,” Universitas Muhammadiyah Yogyakarta.

[5] Kanesalingam, T. 2010. "Motion Tracking Glove for Human-Machine Interaction: Inertial Guidance," McMaster University.

[6] Mapuskar, A. Kharade, A. Kedari, K. Shah, S and Gaikwad, K. 2017. "Robot Controlled Using Hand Motion Recognition," International Research Journal of Engineering and Technology (IRJET), vol. 04, no. 04.

[7] Kaushik, C. 2017. "Hand Gesture Controlled Robot Car," Imperial Journal of Interdisciplinary Research., vol. 3, no. 5.

[8] Singh, R, K. Sarkar, A. Chakravarty, D. Goyal, P. Lodhi, V and Sharma, A. 2015. "Bluetooth communication controlled robot based on gesture recognition," in 2015 IEEE International Transportation Electrification Conference (ITEC), pp. 1-5.

[9] Gupta, P. Bhardwaj, D, D and Jain, R, V. 2017. "Gesture Controlled Mobile Robotic Arm Vehicle Using Accelerometer," International Research Journal of Engineering and Technology (IRJET), vol. 04 , no. 04.

[10] Mustar, Muhamad Yusvin. 2014. "Media Interaksi Manusia-Robot Berbasis Sensor Accelerometer dan Flex (Khusus Gerak Tangan dan Lengan)," M.Eng Thesis. Universitas Gadjah Mada.

[11] Hollocher, D., et al. 2009 "A very low cost, 3-axis, MEMS accelerometer for consumer applications," in Sensors, IEEE, pp. 953-957.

[12] Setiawan, I. Setiyono, B and Susilo, T. B. 2009. "Hasil Uji Kalibrasi Sensor Accelerometer ADXL335," TRANSMISI, vol. 11, no. 3, pp. 118-122.

[13] Datasheet Accelerometer ADXL335. 2010. Analog Devices.

[14] Kadir, A. 2015. From Zero To A Pro Arduino. Yogyakarta: Andi.

[15] Pratama, R, P. Akbar, S, R and Bhawiyuga, A. 2017. "Rancang Bangun Low Power Sensor Node Menggunakan MSP430 Berbasis NRF24L01," Jurnal Pengembangan Teknologi Informasi dan Ilmu Komputer., vol. 1, no. 3.

[16] Permadi, F, A. Kadier, R, E. A and Fatoni, A.2012. "Perancangan dan Implementasi Autonomous Landing Menggunakan Behavior-Based dan Fuzzy Controller pada Quadcopter," Jurnal Teknik ITS, vol. 1, no. 1, pp. A90-A95.

[17] Swamardika, I, B, A. 2013. "Hand Motion Control Untuk Menggerakkan Quadcopter Robot Dengan Menggunakan Sensor Accelerometer Adxl335 Dan Wireless Xbee-Pro Series 160 Mw Berbasis Mikrokontroller ATmega32," Jurnal Ilmiah Mikrotek, vol. 1, no. 2, pp. 47-54.

[18] Pitowarno, E. 2006. Robotika Desain, Kontrol dan Kecerdasan Buatan. Andi. 